\title{
Effect of Secondary Electron Emission Product Factor on Electron and Ion Densities and Electron Kinetic Energy for Ar Gas Discharge Plasma by using OOPIC PRO Simulation Code
}

\author{
Noor A. Ahmed ${ }^{1}$, Mohammed R. Abdulameer ${ }^{2}$ \\ ${ }^{1,2}$ Department of physics, College of Science, University of Baghdad, Baghdad, Iraq
}

\begin{abstract}
In this research, Ar gas discharge plasma was simulated by using OOPIC Pro simulation code. The conditions of the simulation were adopted at simulation time $10^{-6} \mathrm{~s}$, initial electron and ion densities $10^{16} \mathrm{~m}^{-3}$, Ar gas pressure $0.5 \mathrm{mbar}$. Electron and ion densities and electrons kinetic energy were investigated by varying secondary electron emission product factor ( $\gamma)$ and fixing other simulation factors. For $\gamma=0.1,0.2$ and 0.3 it has been found that kinetic energy of electron and electron and ion densities will be affected, the results have been analyzed and discussed.
\end{abstract}

Keywords: gas discharge plasma, electronnumber density, plasma physics, ion number density, secondary electron emission, OOPIC Pro

\section{Introduction}

The passage of electric current through the gas result of an electric field called gas discharge. In the region where the flow of electricity is formed gas-discharge plasma. Its characteristics depend on both the external electric field and the geometry of the gas discharge. The most common type of gaseous discharge is the glow, arc discharge and Townsend takes the place of a cylindrical tube for a fixed electric field where the plasma is a semi-neutral gas of charged and neutral particles showing collective behavior [1].

The term "gas discharge" refers to discharge in a large plate through the air gap, while it is now used in the electric current that is through by the ionized gas. Plasma pattern formation is studiedby coupling Maxwell equations, plasma equations [2].

For the glow-discharge model of Ar, we need a chemical reaction mechanism that is capable of representing all the significant effects of chemistry as a limited rate in the equilibrium of the plasma air [3].

It has not been sufficiently reduced to enable possible computational simulation in two and three dimensions, Computer simulation of the discharge of surface plasma to interact with the flow of sound above pressure of compression is a severe problem on a large scale [4]

The atmospheric pressure of plasma in Ar resulting from electrostatic discharge has attracted considerable attention to a wide range of application such as environmental and biomedical and industrial applications such as air pollution control, sewage cleaning, sterilization, bioremediation, surface treatment, materials analysis, electromagnetic wave modulation, carbon enrichment, nanotube growth [ 5-8 ]

The integration of all aspects of plasma into one single model thus leads to an irreducible model. Particle simulation, which is limited to single-dimensional models, is performed mainly on a parallel panel and has been made an important contribution to the understanding of the non-local effect in the double discharge for capacity [9-10]. In this paper, we will study effect of secondary electron emission product factor on the physical parameter of Ar gas discharge plasma by using OOPIC PRO simulation code, by varying $\gamma$ factor and fixing other simulation parameters.

\section{OPIC Pro Simulation Code Procedure}

OOPIC Pro is a rich mathematical simulation program with two dimensional dimensions in cell simulation was designed to model plasma packages of charged particles generated externally for electric and magnetic fields and neutral gases with low to moderate intensity using a wide range of boundary conditions, the following code has been applied in the current research :-

Dc2

\{

@ description a model of DC discharge

@keywords

@ contact Tech- X Corporation

@ version \$Id : \$

Copyright \&copy ;2008, Tech -X Corporation

See license for condition of use

\} Region

\{

Species

\{

name $=$ electrons

$$
\mathrm{m}=9.11 \mathrm{E}-31
$$$$
q=-1.6 \mathrm{E}-19
$$

collision Model $=1$

\}

Species

\{

name $=$ ions

$\mathrm{m}=6.67 \mathrm{e}-26$

$\mathrm{q}=1.6 \mathrm{E}-19$

collision Model $=0$ 
\}

Grid

\{

$\mathrm{J}=100$

$\mathrm{X} 1 \mathrm{~s}=0.0$

$\mathrm{X} 1 \mathrm{f}=0.1$

$\mathrm{n} 1=1.0$

$\mathrm{K}=10$

$\mathrm{X} 2 \mathrm{~s}=0.0$

$\mathrm{X} 2 \mathrm{f}=0.01$

$\mathrm{n} 2=1.0$

Rule

\{

Limit

$\mathrm{n} 1<0.25$

Fatal $-\mathrm{n} 1<0.25$ grid spacing too non uniform to

ensure

accuracy

\}

Rule

\{

Algebra

$\mathrm{J} * \mathrm{k}>10000$

Warning -- $j * k$ >=10000 may mean memory

problems!

\}

Control

\{

$\mathrm{dt}=1.0 \mathrm{E}-11$

Rule

\{

Limit

$\mathrm{dt}<=0.0$

Fatal - time step must be positive

\}

Electrostatic Flag $=1$

\}

MCC

\{

gas $=\mathrm{Ar}$

pressure $=0.1$

e Species $=$ electrons

i Species $=$ ions

\}

Conductor

\{

$$
\begin{aligned}
& \mathrm{j} 1=100 \\
& \mathrm{k} 1=0 \\
& \mathrm{j} 2=100 \\
& \mathrm{k} 2=10
\end{aligned}
$$

normal $=-1$

Secondary

\{

secondary $=0.2$

sec Species $=$ electrons

i Species $=$ ions

\}

\}

Equipotential

$\mathrm{C}=100$

Frequency $=6.28 \mathrm{E} 5$

Phase $=0$ $\mathrm{j} 1=0$

$\mathrm{j} 2=0$

$\mathrm{k} 1=0$

normal $=1$

\}

Dielectric

\{

$\mathrm{er}=1.0$

$$
\begin{aligned}
& \mathrm{j} 1=0 \\
& \mathrm{j} 2=100 \\
& \mathrm{k} 1=10 \\
& \mathrm{k} 2=10
\end{aligned}
$$

normal $=-1$

Quse Flag = 1

\}

Cylindrical Axis

\{

$$
\begin{aligned}
& \mathrm{j} 1=0 \\
& \mathrm{k} 1=0 \\
& \mathrm{j} 2=0 \\
& \mathrm{k} 2=0
\end{aligned}
$$

normal $=1$

\}

Load

\{

$\mathrm{x} 1 \mathrm{Min} \mathrm{MKS}=0.000$

$\mathrm{x} 1 \mathrm{Max} \mathrm{MKS}=0.1$

x2 Min MKS $=0.000$

$\mathrm{x} 2 \mathrm{Max} \mathrm{MKS}=0.01$

species Name $=$ electrons

density $=1.0 \mathrm{e} 16$

$$
\mathrm{np} 2 \mathrm{c}=2 \mathrm{E} 7
$$

temperature $=5.93 \mathrm{e} 5$

\}

Load

\{

$\mathrm{x} 1 \mathrm{Min}$ MKS $=0.00$

$\mathrm{x} 1 \mathrm{Max} \mathrm{MKS}=0.1$

$\mathrm{x} 2$ Min MKS $=0.000$

$\mathrm{x} 2$ Max MKS $=0.01$

species Name $=$ ions

density $=1.0 \mathrm{e} 16$ $\mathrm{np} 2 \mathrm{c}=2 \mathrm{E} 7$

temperature $=353$

\}

\}

We will vary $\gamma$ to three different values to investigate its effect on the kinetic energy of the electrons in the plasma and on the electron and ion densities, with simulation time $\mathrm{t}=10^{-6} \mathrm{~s}$ and fixing the density of electron and ion and the type of gas (Ar gas) and its pressure as follow:-

$\left(\gamma=0.1\right.$, gas $\left.=A r, \mathrm{n}_{\mathrm{e}}, \mathrm{n}_{\mathrm{i}}=10^{16} \mathrm{~m}^{-3}, \mathrm{p}=0.5 \mathrm{mbar}, \mathrm{dt}=10^{-6} \mathrm{~s}\right)$ ( $=0.2$, gas $\left.=\mathrm{Ar}, \mathrm{n}_{\mathrm{e}}, \mathrm{n}_{\mathrm{i}}=10^{16} \mathrm{~m}^{-3}, \mathrm{p}=0.5 \mathrm{mbar}, \mathrm{dt}=10^{-6} \mathrm{~s}\right)$ $\left(\gamma=0.3\right.$, gas $\left.=\mathrm{Ar}, \mathrm{n}_{\mathrm{e}}, \mathrm{n}_{\mathrm{i}}=10^{16} \mathrm{~m}^{-3}, \mathrm{p}=0.5 \mathrm{mbar}, \mathrm{dt}=10^{-6} \mathrm{~s}\right)$

\section{Results and Discussion}

The figures (1),(2) and (3) represent the time profile of the kinetic energy of electrons in Ar gas discharge plasma at $\mathrm{Ar}$ gas pressure $\mathrm{P}=0.5 \mathrm{mbar}$, the initial $\mathrm{n}_{\mathrm{e}}, \mathrm{n}_{\mathrm{i}}=10^{16} \mathrm{~m}^{-3}$ and simulation time $10^{-6} \mathrm{~s}$ with different values of secondary electron emission product $\gamma(0.1,0.2,0.3)$ respectively.

Volume 6 Issue 7, July 2017

www.ijsr.net

Licensed Under Creative Commons Attribution CC BY 


\section{International Journal of Science and Research (IJSR) \\ ISSN (Online): 2319-7064}

Index Copernicus Value (2015): 78.96 | Impact Factor (2015): 6.391

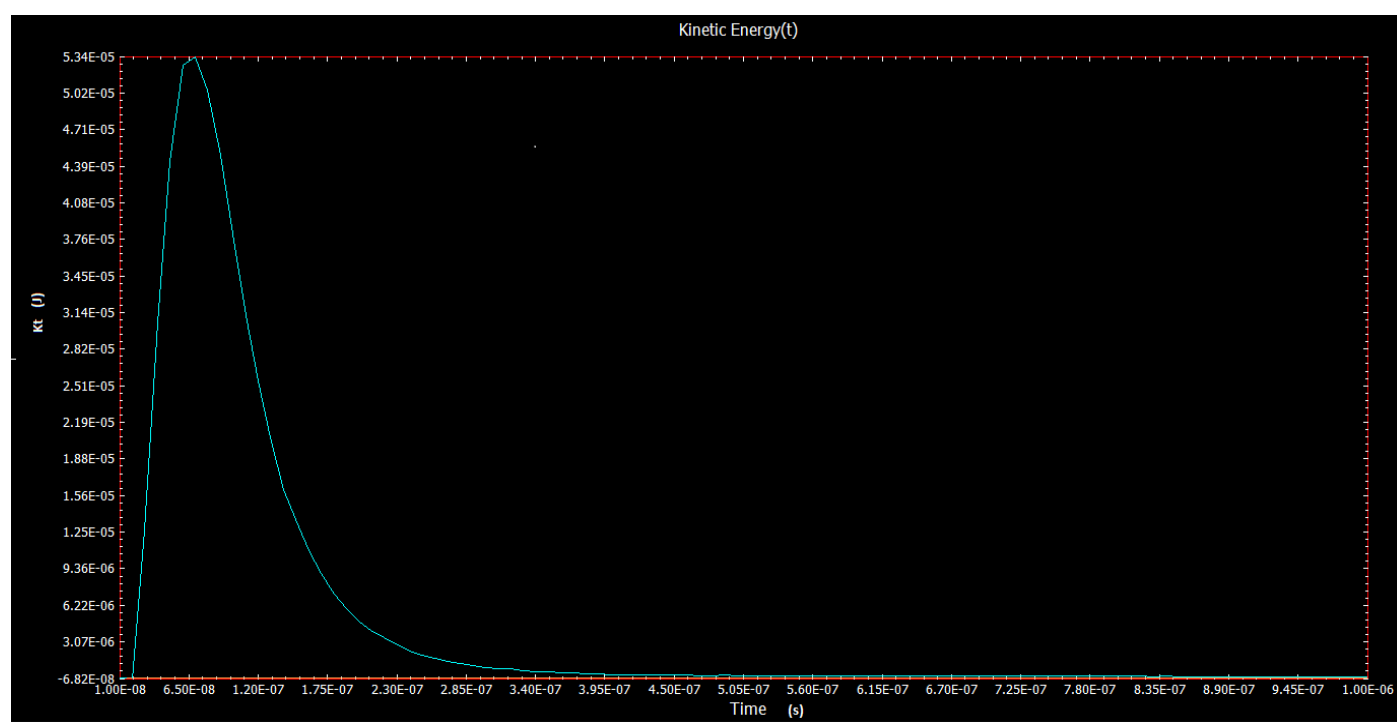

Figure 1: The time profile of the kinetic energy of electrons in Ar gas discharge plasma at $\mathrm{Ar}$ gas pressure $\mathrm{P}=0.5 \mathrm{mbar}$, the initial $\mathrm{n}_{\mathrm{e}}, \mathrm{n}_{\mathrm{i}}=10^{16} \mathrm{~m}^{-3}$, at $\gamma=0.1$

When simulation time $\mathrm{t}=10^{-6} \mathrm{~s}$, kinetic energy value exceeds its original value, where its highest value is $5.34 \times 10^{-5} \mathrm{~J}$, the shape becomes a curve where the curve starts at its value and gradually decreases until its lowest value $4.5 \times 10^{-7} \mathrm{~J}$, i.e. kinetic energy values increase as time values increase.

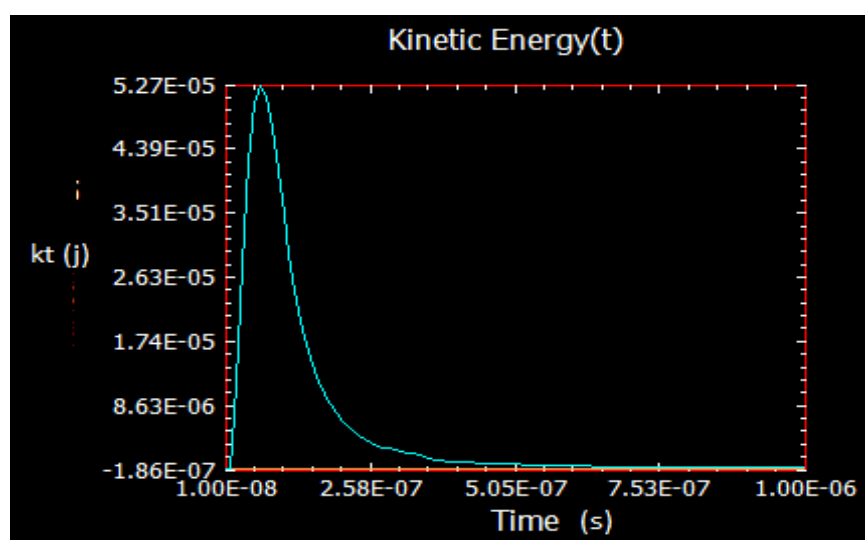

Figure 2: The time profile of the kinetic energy of electrons in $\mathrm{Ar}$ gas discharge plasma at $\mathrm{Ar}$ gas pressure $\mathrm{P}=0.5 \mathrm{mbar}$, the initial ne, $n i=10^{16} \mathrm{~m}^{-3}$, at $\gamma=0.2$

When the simulation time $\mathrm{t}=10^{-6} \mathrm{~s}$, the value of $\mathrm{kt}$ is less than its original value at $\gamma=0.1$ for the same time, where the highest value is $\mathrm{kt}=5.27 \times 10^{-5} \mathrm{~J}$, and the shape is curved where the curve starts at its highest value and gradually decreases until it reaches the lowest value of $\mathrm{kt}=5.05 \times 10^{-7} \mathrm{~J}$ ,the value of kt decreases when the value of $\gamma$ increase

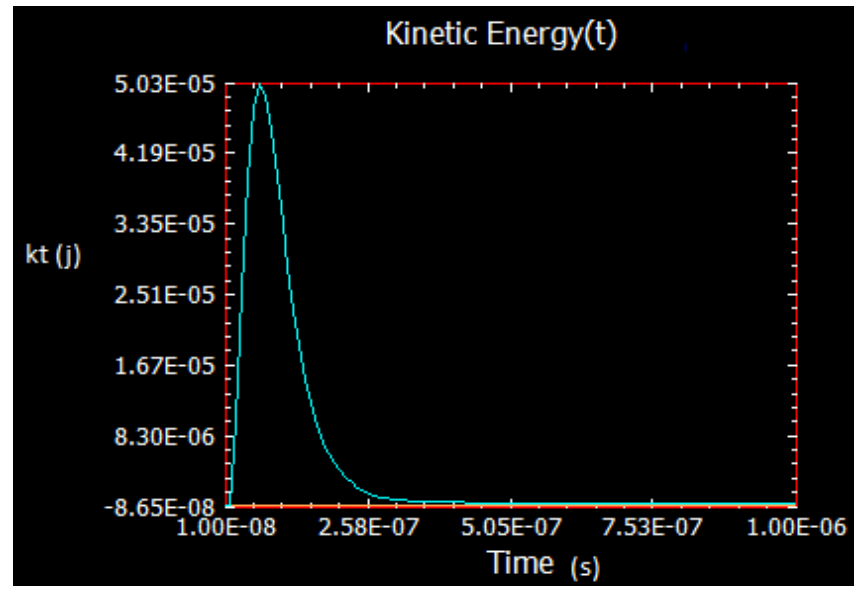

Figure 3: The time profile of the kinetic energy of electrons in Ar gas discharge plasma at Ar gas pressure $\mathrm{P}=0.5 \mathrm{mbar}$, the initial ne, $n i=10^{16} \mathrm{~m}^{-3}$, at $\gamma=0.3$

At simulation time $\mathrm{t}=10^{-6} \mathrm{~s}$, the value of $\mathrm{kt}$ increases from its original value at time $\mathrm{t}=10^{-8} \mathrm{~s}$, where it reaches its highest value of $\mathrm{kt}=5.03 \times 10^{-5} \mathrm{~J}$, the shape is curved beginning at a certain point $\mathrm{kt}=-8.65 \times 10^{-8} \mathrm{~J}$ unitil it reaches its highest value.

At long distances, the kinetic energy of the electrons is lost and experimentally dissipated under the effect of friction and collisions with the background gas atoms. Also, the electrons will lose their kinetic energy and speed due to collision and ionization of the gas atoms. In addition, recombination between electrons and ions plays an effective role in reducing the speed of the electrons when the axial distance increases from the target surface of cathode.

The figures (4),(5),(6),(7),(8) and (9) represent the spatial profile of the electron and ion densities in Ar gas discharge plasma at Ar gas pressure $\mathrm{P}=0.5 \mathrm{mbar}$, the initial $\mathrm{n}_{\mathrm{e}}, \mathrm{n}_{\mathrm{i}}=10^{16} \mathrm{~m}$ and simulation time $10^{-6} \mathrm{~s}$ with different values of secondary electron emission product $\gamma(0.1,0.2,0.3)$ respectively. 


\section{International Journal of Science and Research (IJSR) \\ ISSN (Online): 2319-7064}

Index Copernicus Value (2015): 78.96 | Impact Factor (2015): 6.391

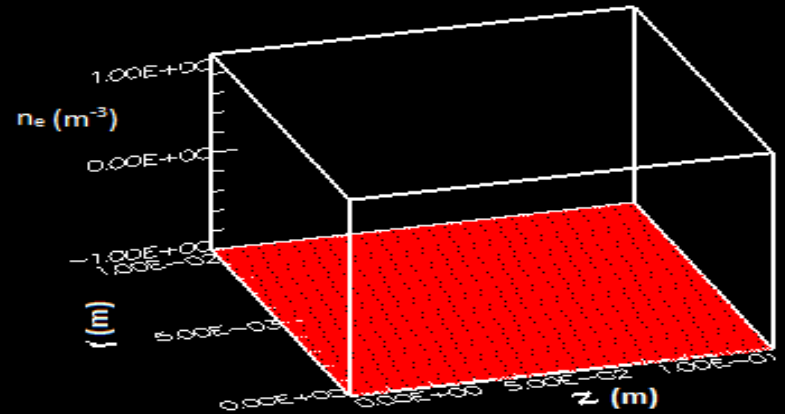

Figure 4: The spatial profile of the electron density in $\mathrm{Ar}$ gas discharge plasma at Ar gas pressure $\mathrm{P}=0.5 \mathrm{mbar}$, the initial ne, $n i=10^{16} \mathrm{~m}^{-3}$, at $\gamma=0.1$

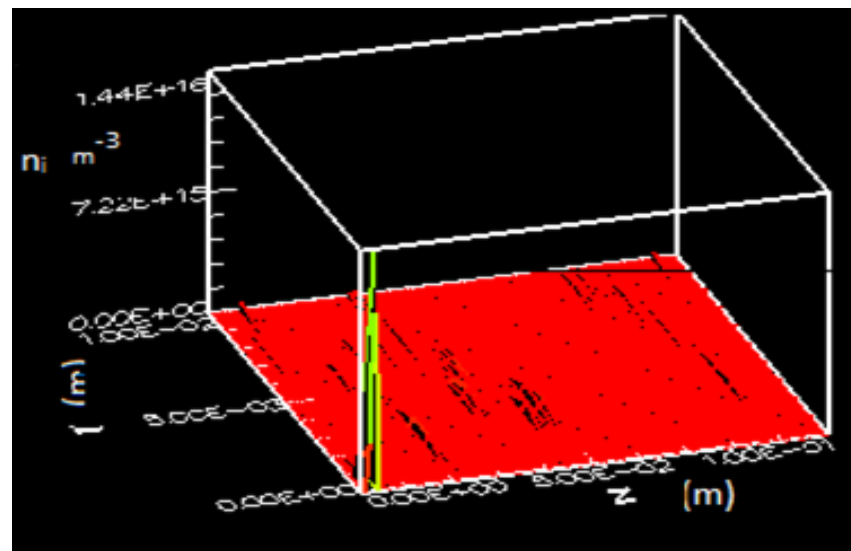

Figure 5: The spatial profile of the ion density in Ar gas discharge plasma at Ar gas pressure $\mathrm{P}=0.5 \mathrm{mbar}$, the initial $\mathrm{ne}, \mathrm{ni}=10^{16} \mathrm{~m}^{-3}$, at $\gamma=0.1$

At time $10^{-6} \mathrm{~s}$, the value of the electron density $\mathrm{n}_{\mathrm{e}}$ is less than the previous value at $10^{-8} \mathrm{~s}$, where the value becomes $1 \times 10^{-2}$ $\mathrm{m}^{-3}$, and the shape becomes a straight line. At time $\mathrm{t}=10^{-6} \mathrm{~s}$, the highest value of $n_{i}$ is $7.44 \times 10^{16} \mathrm{~m}^{-3}$, which is less than the original value at time $t=10^{-8} \mathrm{~s}$ and the shape is a straight line and there is one peak at the highest value of $n_{i}$

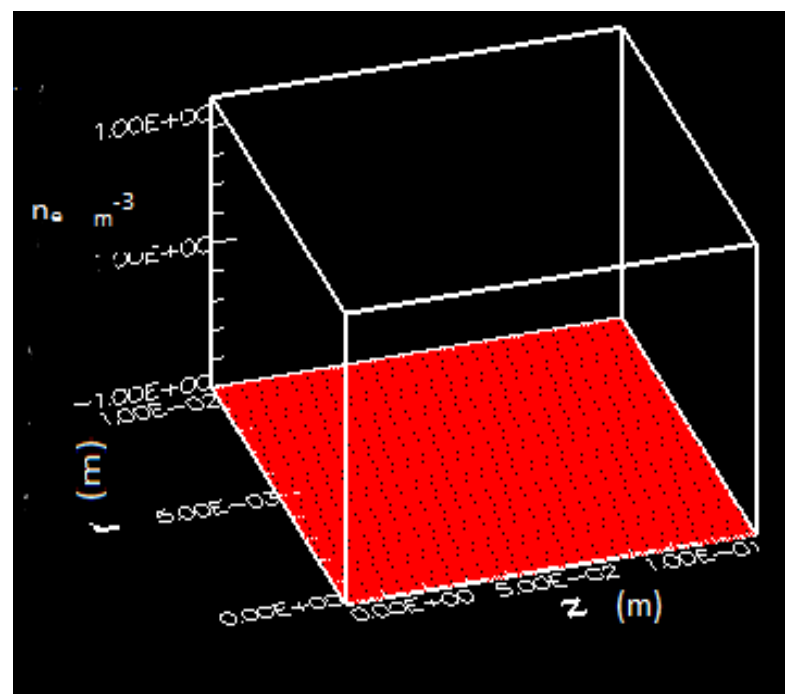

Figure 6: The spatial profile of the electron density in $\mathrm{Ar}$ gas discharge plasma at Ar gas pressure $\mathrm{P}=0.5 \mathrm{mbar}$, the initial ne, $n i=10^{16} \mathrm{~m}^{-3}$, at $\gamma=0.2$

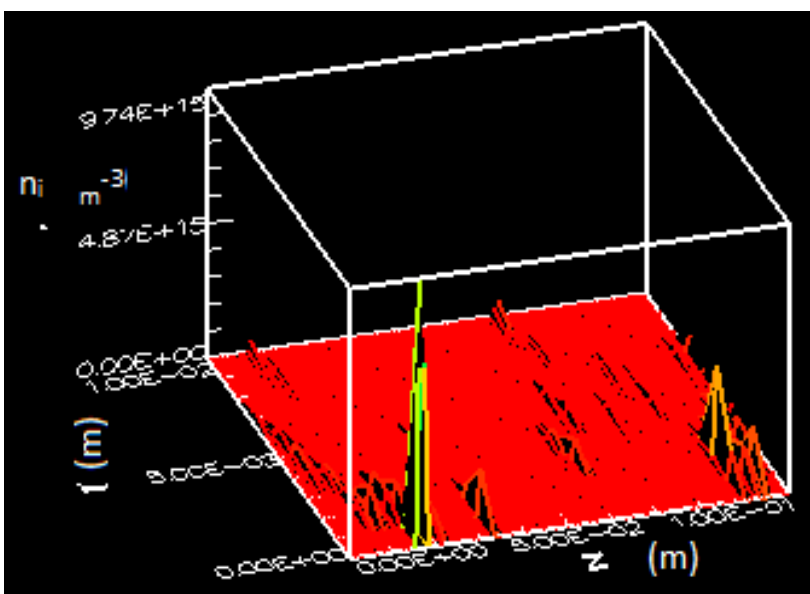

Figure 7: The spatial profile of the ion density in Ar gas discharge plasma at Ar gas pressure $\mathrm{P}=0.5 \mathrm{mbar}$, the initial $\mathrm{ne}, \mathrm{ni}=10^{16} \mathrm{~m}^{-3}$, at $\gamma=0.2$

$\mathrm{n}_{\mathrm{e}}$ values remain constant and the shape becomes a straight line. When the time of simulation $t=10^{-6} \mathrm{~s}$, the highest value of $\mathrm{n}_{\mathrm{i}}$ is $9.74 \times 10^{15} \mathrm{~m}^{-3}$ where its value is less than the original value when $\gamma=0.1$ at the same time. The shape contains a straight line and there is one value at the highest values of the $\mathrm{n}_{\mathrm{i}}$.

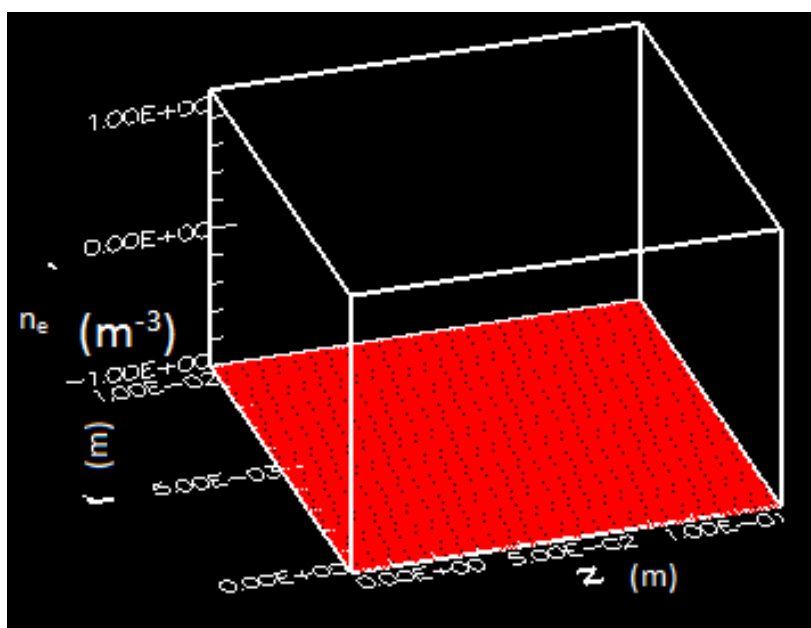

Figure 8: The spatial profile of the electron density in $\mathrm{Ar}$ gas discharge plasma at Ar gas pressure $\mathrm{P}=0.5 \mathrm{mbar}$, the initial ne, $n i=10^{16} \mathrm{~m}^{-3}$, at $\gamma=0.3$

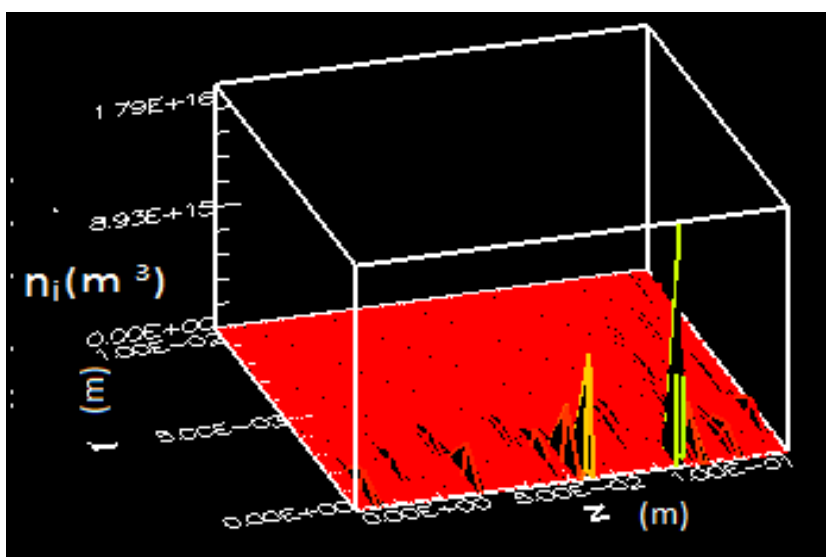

Figure 9: The spatial profile of the ion density in Ar gas discharge plasma at Ar gas pressure $\mathrm{P}=0.5 \mathrm{mbar}$, the initial $\mathrm{ne}, \mathrm{ni}=10^{16} \mathrm{~m}^{-3}$, at $\gamma=0.3$

Volume 6 Issue 7, July 2017 www.ijsr.net 


\section{International Journal of Science and Research (IJSR) \\ ISSN (Online): 2319-7064}

Index Copernicus Value (2015): 78.96 | Impact Factor (2015): 6.391

At simulation time $t=10^{-6} \mathrm{~s}$, we find that the highest value of $\mathrm{n}_{\mathrm{e}}$ is $1 \times 10^{-2} \mathrm{~m}^{-3}$, it is decreasing as time increases and it is in a straight line. The value of $n_{i}$ is less than the original value mentioned in the time $\mathrm{t}=10^{-8} \mathrm{~s}$, where the highest values are $\mathrm{n}_{\mathrm{i}}=1.79 \times 10^{16} \mathrm{~m}^{-3}$ and are in a straight line and there is a high peak at the highest value mentioned above.

The recombination between electrons and ions at far distances is responsible for the reduction of $n_{e}$. In the beginning of $\mathrm{z}$, the various types of ionization operations are dominant in increasing the production of electrons and thus increase the density.At medium distances, elastic collisions and diffusion processes play an important role in reducing the density and number of electrons and causes the recombination between the negative electron and positive ion.

\section{Conclusions}

OOPIC Pro simulation software has been used to study the effect of secondary electron emission product $\gamma$ on kinetic energy of electrons and electrons and ions densities in $\mathrm{Ar}$ gas discharge plasma at simulation time $10^{-6} \mathrm{~s}$, initial electron and ion densities $10^{16} \mathrm{~m}^{-3}$, Ar background gas pressure $0.5 \mathrm{mbar}$ for three different values of $\gamma=0.1,0.2$ and 0.3 . thetime profile of kinetic energy of electrons and spatial profile of electron and ion densities have been plotted and discussed. The effect of secondary electron emission product $\gamma$ on kinetic energy of electrons and electrons and ions densitieshas been verified. As $\gamma$ increases the kinetic energy of electrons decreases due to loss in electrons kinetic energy by collision with Ar gas atoms and recombination withionsat far distances from the cathode target. electron density nearly doesn't affected with varying $\gamma$ while ion density decreases with increasing $\gamma$ factor.Elastic collisions and diffusion processes play an important role in reducing the density and number of electrons and ions, then it causes the recombination between the negative electron and positive ion.

\section{References}

[1] Boris M. Smirnov,"Physics of ionized gases",John Wiley, and Sons,Inc.,New York,USA,chapter one,2001.

[2] Guo-QiangZhu,"Modeling of plasma dynamics and pattern formation during high pressure microwave breakdown in air",M.Sc.thesis, Universite de Toulouse, 2012.

[3] ShankavMahadev, and LaxminarayanL.Raja,"Simulation of Direct-current Air surface plasma Discharge in supersonic flow", 47th AIAA Aerospace Sciences Meeting Including The New Horizons Forum and Aerospace Exposition, p.p. 5-8, 2009.

[4] Z.Machala,M.Janda ,K.Hensel ,I.Jedlovsky , L.Lestinska,V.Foltin , V.Martisovits ,
M.Morvova,"Emission spectroscopy of atmospheric pressure plasmas for bio-medical and environmental applications ", Journal of Molecular Spectroscopy , vol.243,p.p.194-201, 2007.

[5] Ali A-k.Hussain, Kadhim A.A.ALHamdani,Mohammed R.Abdulameer, "Simulation of plasma properties in magnetron sputtering with Kr gas",
International Journal of Application of Innovation in Engineering and Management (IJAIEM, vol.2,p.p.290296,2007.

[6] Y.H.Choi ,J.H Kim , and Y.S. Hwang,"Onedimensional discharge simulation of Nitrogen DBD atmospheric pressure plasma", thin solid films,vol.506507,p.p. 389-395 , 2006.

[7] Wang Yi-Nan, Lin Yue ,Zheng shu, and Lin GuoQiang,"Numerical study on the characteristics of Nitrogen discharge at high pressure with induced plasma", chin phys., vol.21, No.7, 2012.

[8] H. C.Kim , F.Iza , S. S. Yang , M.Radmilovic , Radjenovic and J. K. Lee ,'Particle and fluid simulation of low- temperature plasma discharge: benchmarks and kinetic effects",Journal of phycics D:Appledphysics, vol.38 , p.p.238-301, 2005.

[9] M.Mankour, A.W.Belarbi, and K.Hartani ,'Modelingof atmospheric glow discharge characteristics ", vol.65, No.1, p.p.230-245,2013.

[10] EmrahErden, "Simulation of glow discharge plasmas by using parallel particlein cell / montecarlo collision method: the effects of number ofsuper particles used in the simulations", M.Sc. thesis, Middle east technical university, 2013. 